\title{
A study of carotid intima-media thickness in GH-deficient Japanese adults during onset among adults and children
}

\author{
Masahiro Murata, Hidesuke Kaji ${ }^{2}$, Ishikazu Mizuno, Tatsuya Sakurai, Keiji Iida, Yasuhiko Okimura ${ }^{1}$ and \\ Kazuo Chihara \\ Third Division, Department of Medicine, and ${ }^{1}$ Department of Basic Allied Medicine, Kobe University School of Medicine, Kobe, 650-0017, \\ Japan and ${ }^{2}$ Department of Physiology/Metabolism, College of Nursing Art and Science, Hyogo, Akashi 673-8588, Japan \\ (Correspondence should be addressed to H Kaji; Email: hidesuke_kaji@cnas-hyogo.ac.jp)
}

\begin{abstract}
Objectives: Increased carotid intima-media thickness (IMT) has been reported among Caucasian adult GH-deficient (AGHD) patients, but not Japanese. Also, it is known that the clinical and biochemical characteristics of AGHD patients are somewhat different based on the onset of the disease in either childhood or adult life. Nevertheless, there has been no study comparing the magnitude of the deviation of their IMT from normal subjects between child-onset (CO) and adult-onset (AO) patients in terms of $\mathrm{Z}$ score. The aim of this study, therefore, was first to examine whether Japanese AGHD patients have a risk of early development of atherosclerosis similar to Caucasian patients and secondly to assess the difference in the onset and in progression of atherosclerosis.

Design and subjects: Thirty-four patients (17 CO-AGHD, age $29 \pm 7$ years, body mass index (BMI) $24 \pm 3.8 \mathrm{~kg} / \mathrm{m}^{2}$ and 17 AO-AGHD, age $48 \pm 12$ years, BMI $23 \pm 3.6 \mathrm{~kg} / \mathrm{m}^{2}$ ) and 34 age- and sexmatched healthy controls (17 CO controls and $17 \mathrm{AO}$ controls) were enrolled in the present study. Blood samples were taken for measurements of lipids, lipoproteins and IGF-I. Subsequently, patients underwent IMT assessment.

Results: CO patients were significantly younger than AO patients. The duration of GH-deficiency in CO patients was significantly longer than that in AO patients. Serum triglyceride (TG) was significantly higher in $\mathrm{CO}$ patients than in $\mathrm{CO}$ controls $(P<0.05)$. Serum total cholesterol and TG were significantly higher in AO patients than in AO controls $(P<0.01)$. The IMT was significantly greater in $\mathrm{CO}$ and $\mathrm{AO}$ patients $(0.82 \pm 0.08$ and $0.79 \pm 0.03 \mathrm{~mm})$ than in $\mathrm{CO}$ and $\mathrm{AO}$ controls $(0.59 \pm 0.02$ and $0.68 \pm 0.03 \mathrm{~mm}, P<0.01$ and $P<0.01$ respectively). There was no significant difference in raw values of IMT between $\mathrm{CO}$ and AO patients. However, the Z score of IMT calculated using normal Japanese IMT values was significantly higher in CO than in AO patients $(2.07 \pm 0.68$ vs $0.35 \pm 0.48, P<0.05)$.

Conclusions: These findings suggest that GH deficiency appears to increase an atherosclerotic risk in Japanese AGHD patients, as with Caucasians, and to cause more extensive IMT thickening in CO-AGHD than AO-AGHD patients.
\end{abstract}

European Journal of Endocrinology 148 333-338

\section{Introduction}

Recent retrospective studies have revealed that adult patients with hypopituitarism under conventional hormone replacement treatment by thyroid hormone, adrenal and/or sex steroids show a higher mortality rate, mostly attributable to vascular disorders, and higher morbidity from diseases related to atherosclerosis than general healthy subjects (1). The early development of atherosclerosis in these patients is thought to be at least partly caused by growth hormone $(\mathrm{GH})$ deficiency. The severity of atherosclerosis has been assessed by measurement of carotid intima-media thickness (IMT), a well-accepted marker of vascular risks, by means of high resolution ultrasonography. IMT was found to increase in adult Caucasian patients with hypopituitarism (2) as well as child-onset (CO) adult GH-deficient (AGHD) patients (3). Furthermore, a 1 year GH treatment of AGHD patients resulted in a significant amelioration of their increased IMT (4).

GH-deficient (GHD) patients also have associated abnormal metabolism of lipid and carbohydrate, which may contribute to an increased risk of vascular disease (5-13). Administration of $\mathrm{GH}$ to these patients reduced adipose tissue and increased lean body mass $(14,15)$, increased physical and cardiac performance (16-19), normalized lipid metabolism (9) and improved quality of life $(20,21)$. However, AGHD may not be a 
homogeneous clinical entity because clinical characteristics of AGHD appear to be somewhat different between $\mathrm{CO}$ and adult-onset (AO) patients. Attanasio et al. (22) reported that the body height, weight, body mass index (BMI), lean body mass and the waist/hip ratio of $\mathrm{AO}$ patients were all significantly greater than in $\mathrm{CO}$ patients but there were no differences in serum total cholesterol (TC), low-density lipoprotein cholesterol (LDL-C) and high-density lipoprotein cholesterol (HDL-C) levels between the two groups. We wondered whether the atherosclerotic risk is similar among $\mathrm{AO}$ and $\mathrm{CO}$ patients. To the best of our knowledge, there is no report comparing the $\mathrm{Z}$ score of IMT among AO and CO patients so far. Furthermore, IMT in Japanese AGHD patients remains not definitively studied.

The aim of this study was to assess the progression of atherosclerosis by means of IMT measurement in Japanese AGHD patients and to analyse how it differs in a comparison between Japanese CO and AO patients.

\section{Patients and methods}

\section{Patients}

Thirty-four patients (17 CO, 10 males and 7 females, age $29 \pm 7$ years, height $1.62 \pm 0.02 \mathrm{~m}$, BMI $24 \pm 3.8 \mathrm{~kg} / \mathrm{m}^{2}$ and $17 \mathrm{AO}, 10$ males and 7 females, age $48 \pm 12$ years, height $1.61 \pm 0.02 \mathrm{~m}, \mathrm{BMI} 23 \pm 3.6 \mathrm{~kg} / \mathrm{m}^{2}$ ) and
34 healthy controls (17 CO controls and 17 AO controls), comparable in gender and age distribution were enrolled in the present study (Table 1). The aetiology of hypopituitarism was varied among the patients as shown in Table 1. In all patients, GH deficiency was diagnosed as peak serum GH levels below $3 \mu \mathrm{g} / \mathrm{l}$ in insulin tolerance tests.

All CO patients were treated with $\mathrm{GH}$ at the dose of $0.5 \mathrm{IU} / \mathrm{kg}$ body weight per week for a period ranging from 1 to 11 years, but $\mathrm{GH}$ administration discontinued at least 3 years before entry into the study, whereas none of the AO patients had been given $\mathrm{GH}$ therapy (Table 1). All patients had multiple pituitary deficiency and were under replacement therapy with various hormones such as thyroxine, hydrocortisone or desmopressin at standard doses. All patients with hypogonadism below age 50 except four $\mathrm{CO}$ and two AO patients had sex hormone replacement. No medications other than hormones were prescribed. Patients known to have diabetes, cardiovascular diseases or hypertension were excluded. All participants gave their informed consent, and the protocol was approved by the local institutional review board in our hospital.

\section{Protocol}

All participants were studied in the postabsorptive state after a $12 \mathrm{~h}$ overnight fast. Blood pressure (systolic and

Table 1 Characteristics of the study population. Values are means \pm S.D.

\begin{tabular}{|c|c|c|c|c|}
\hline & CO controls & CO-AGHD & AO controls & AO-AGHD \\
\hline No. & 17 & 17 & 17 & 17 \\
\hline Age (years) & $29 \pm 7$ & $29 \pm 7^{b}$ & $48 \pm 12$ & $48 \pm 12$ \\
\hline $\operatorname{Sex}(M / F)$ & $10 / 7$ & $10 / 7$ & $10 / 7$ & $10 / 7$ \\
\hline Height (m) & $1.67 \pm 0.07$ & $1.62 \pm 0.08^{a}$ & $1.64 \pm 0.02$ & $1.61 \pm 0.02^{c}$ \\
\hline BMI $\left(\mathrm{kg} / \mathrm{m}^{2}\right)$ & $22 \pm 1.6$ & $24 \pm 3.8^{a}$ & $22 \pm 3.2$ & $23 \pm 3.6$ \\
\hline Smoking & $2 / 17$ & $2 / 17$ & $2 / 17$ & $2 / 17$ \\
\hline Duration of GHD & - & $21 \pm 9^{b}$ & - & $14 \pm 9$ \\
\hline Duration of $\mathrm{GH}$ treatment & - & $7 \pm 4$ & - & 0 \\
\hline PAS $(\mathrm{mmHg})$ & $109 \pm 15$ & $108 \pm 15$ & $115 \pm 7$ & $111 \pm 11$ \\
\hline PAD (mmHg) & $62 \pm 9$ & $71 \pm 11$ & $73 \pm 9$ & $72 \pm 12$ \\
\hline \multicolumn{5}{|l|}{ Aetiology (no.) } \\
\hline Pituitary adenoma & - & 1 & - & 12 \\
\hline Craniopharyngioma & - & 3 & - & 1 \\
\hline Germinoma & - & 5 & - & 0 \\
\hline Optic glioma & - & 1 & - & 0 \\
\hline Sheehan's syndrome & - & 0 & - & 1 \\
\hline Trauma & - & 1 & - & 2 \\
\hline Idiopathic & - & 6 & - & 1 \\
\hline \multicolumn{5}{|l|}{ Replacement treatment } \\
\hline Thyroxine & - & 15 & - & 14 \\
\hline Cortisol & - & 14 & - & 14 \\
\hline Sex steroids & - & 9 & - & 7 \\
\hline Desmopressin & - & 6 & - & 1 \\
\hline $\mathrm{TC}(\mathrm{mg} / \mathrm{dl})$ & $188 \pm 15$ & $211 \pm 48$ & $186 \pm 16$ & $209 \pm 24^{c}$ \\
\hline LDL-C (mg/dl) & $109 \pm 14$ & $126 \pm 35$ & $111 \pm 14$ & $119 \pm 19$ \\
\hline $\mathrm{HDL}-\mathrm{C}(\mathrm{mg} / \mathrm{dl})$ & $60 \pm 9$ & $55 \pm 18$ & $59 \pm 10$ & $61 \pm 24$ \\
\hline Total TG (mg/dl) & $58.8 \pm 27.6$ & $159 \pm 121^{a}$ & $78.3 \pm 36.2$ & $143 \pm 79^{c}$ \\
\hline IGF-I (ng/ml) & - & $63 \pm 35$ & - & $60 \pm 24$ \\
\hline Fasting glucose (mg/dl) & $81 \pm 12$ & $80 \pm 13$ & $82 \pm 9$ & $80 \pm 10$ \\
\hline
\end{tabular}

${ }^{\mathrm{a} P}<0.05$ vs $\mathrm{CO}$ control, ${ }^{\mathrm{b}} P<0.01$ vs AO-AGHD, ${ }^{\mathrm{c}} P<0.01$ vs AO control. PAS, systolic blood pressure; PAD, diastolic blood pressure. 
diastolic) was measured using the sphygmomanometric method. Blood samples were taken for measurements of lipids, lipoproteins and insulin-like growth factor-I (IGF-I). Then, patients underwent ultrasonographic scanning of the carotid arteries according to a recent Japanese study (24) by a trained physician and were photographed. The assessment of IMT was performed by a high resolution echo-colour Doppler system (LOGIQ700MR; GE Yokogawa Medical System, Tokyo, Japan). Scanning of the extracranial carotid arteries in the neck was performed bilaterally in three different longitudinal projections: anterior-oblique, lateral and posterior-oblique as well as the transverse projection. Three determinations of intima plus medial thickness were conducted at the site of the greatest thickness and at two points, $1 \mathrm{~cm}$ upstream and $1 \mathrm{~cm}$ downstream from the site of the greatest thickness. These three values were averaged. The greatest value among the six averaged intima plus medial thickness (three from the left and three from the right) was used as the representative IMT value for each individual. The coefficients of variation of the measurements were less than $3 \%$. All scans were read by an independent physician, blinded as to the clinical status of the subjects. This method is well-known and valid in Japan, although performed in a different way from most previous investigation of IMT in GHD patients. The Z score of IMT was defined as the standard deviation of mean IMT values in normal Japanese of every 10 year age cohort (23).

Serum TC, HDL-C, serum triglyceride (TG) and plasma glucose levels were assayed by standard laboratory techniques. LDL-C was estimated by the Friedewald equation. Serum IGF-I levels were determined by an IRMA after extraction (SRL, Inc., Tokyo, Japan).

\section{Statistical analysis}

Data are expressed as means \pm s.E.M. in Figures and means \pm s.D. in the Table. Statistical analysis was performed using one-way repeated measures ANOVA in both the Table and Fig. 1, and using Student's $t$-test in Fig. 2. $P<0.05$ was considered significant.

\section{Results}

The comparison of the background data for the $\mathrm{CO}$ and AO patients revealed the age and the duration of $\mathrm{GH}$ deficiency to be significantly different among the two groups. The average age of $\mathrm{CO}$ patients was significantly younger than that of AO patients $(P<0.001)$, and the duration of GH deficiency in $\mathrm{CO}$ patients was significantly longer than in AO patients $(P<0.01)$. However, all $\mathrm{CO}$ patients had a past history of $\mathrm{GH}$ treatment to ameliorate their short stature. The duration of $\mathrm{GH}$ administration was varied among patients. The spectrum of causes of GH deficiency was entirely different

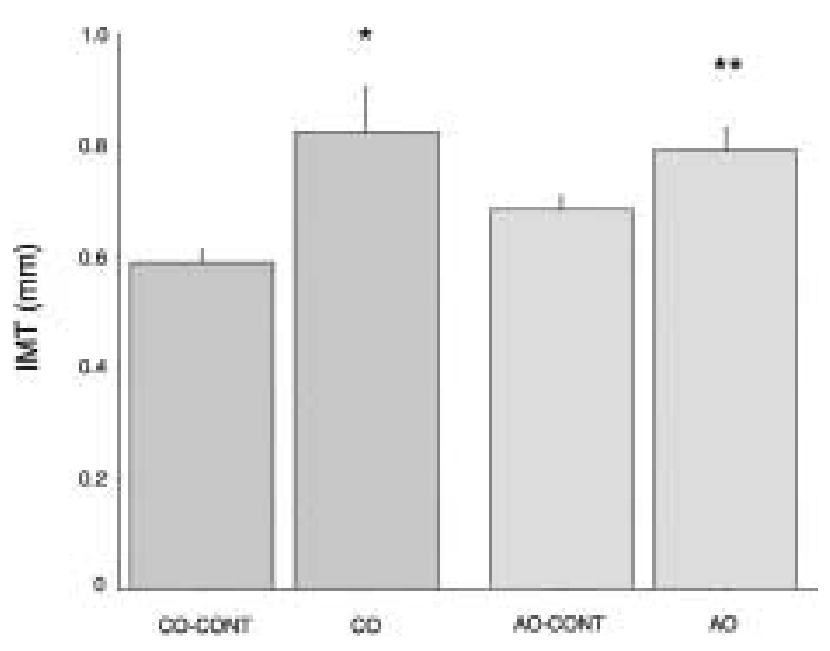

Figure 1 Carotid IMT in CO-AGHD, CO control, AO-AGHD and AO control. The values represent the means \pm s.E.M. ${ }^{\star} P<0.01$ vs $\mathrm{CO}$ control; ${ }^{\star \star} P<0.01$ vs $\mathrm{AO}$ control.

between $\mathrm{CO}$ and $\mathrm{AO}$ patients. The prevalence of cigarette smoking, blood pressure and hormone replacement were similar among the $\mathrm{CO}$ and $\mathrm{AO}$ patients (Table 1).

Furthermore, compared with the data of control subjects, height was significantly shorter in CO patients than in $\mathrm{CO}$ controls and was significantly shorter in AO patients than in $\mathrm{AO}$ controls $(P<0.05)$. BMI was significantly higher in $\mathrm{CO}$ patients than $\mathrm{CO}$ controls $(P<0.01)$, but not significantly different among AO patients and AO controls. Serum TC, LDL-C, HDL-C and glucose were similar in CO patients and CO controls. Serum TG was significantly higher in $\mathrm{CO}$ patients than in $\mathrm{CO}$ controls $(P<0.05)$. Serum LDL-C, HDL-C and glucose were similar in AO patients and AO controls. Serum TC and TG were significantly higher in AO patients than in $\mathrm{AO}$ controls $(P<0.01$ and $P<0.01$ respectively). However, no difference was observed in serum TC, LDL-C, HDL-C, TG, IGF-I and glucose and in BMI among $\mathrm{CO}$ and $\mathrm{AO}$ patients (Table 1 ).

The IMT in AGHD patients was significantly greater than that in control subjects irrespective of the onset of their GH deficiency (CO patients, $0.82 \pm 0.08 \mathrm{~mm}$ vs $\mathrm{CO}$ controls, $0.59 \pm 0.02 \mathrm{~mm}, P<0.01$; AO patients, $0.79 \pm 0.03 \mathrm{~mm}$ vs AO controls, $0.68 \pm 0.03 \mathrm{~mm}$, $P<0.01$ ) (Fig. 1). Height and BMI are major determinants of IMT. CO and AO patients were significantly shorter in height in comparison with the respective controls (Table 1). Therefore, IMT was corrected by height. IMT/height was still significantly greater in CO patients than in CO controls $(0.508 \pm 0.20$ vs $0.365 \pm 0.064, P<0.01)$. IMT/height was also significantly greater in $\mathrm{AO}$ patients than in $\mathrm{AO}$ controls (0.491 \pm 0.0 .028 vs $0.425 \pm 0.021, P<0.05)$. Since BMI was significantly higher in $\mathrm{CO}$ patients than $\mathrm{CO}$ controls, IMT was corrected by BMI in CO patients 


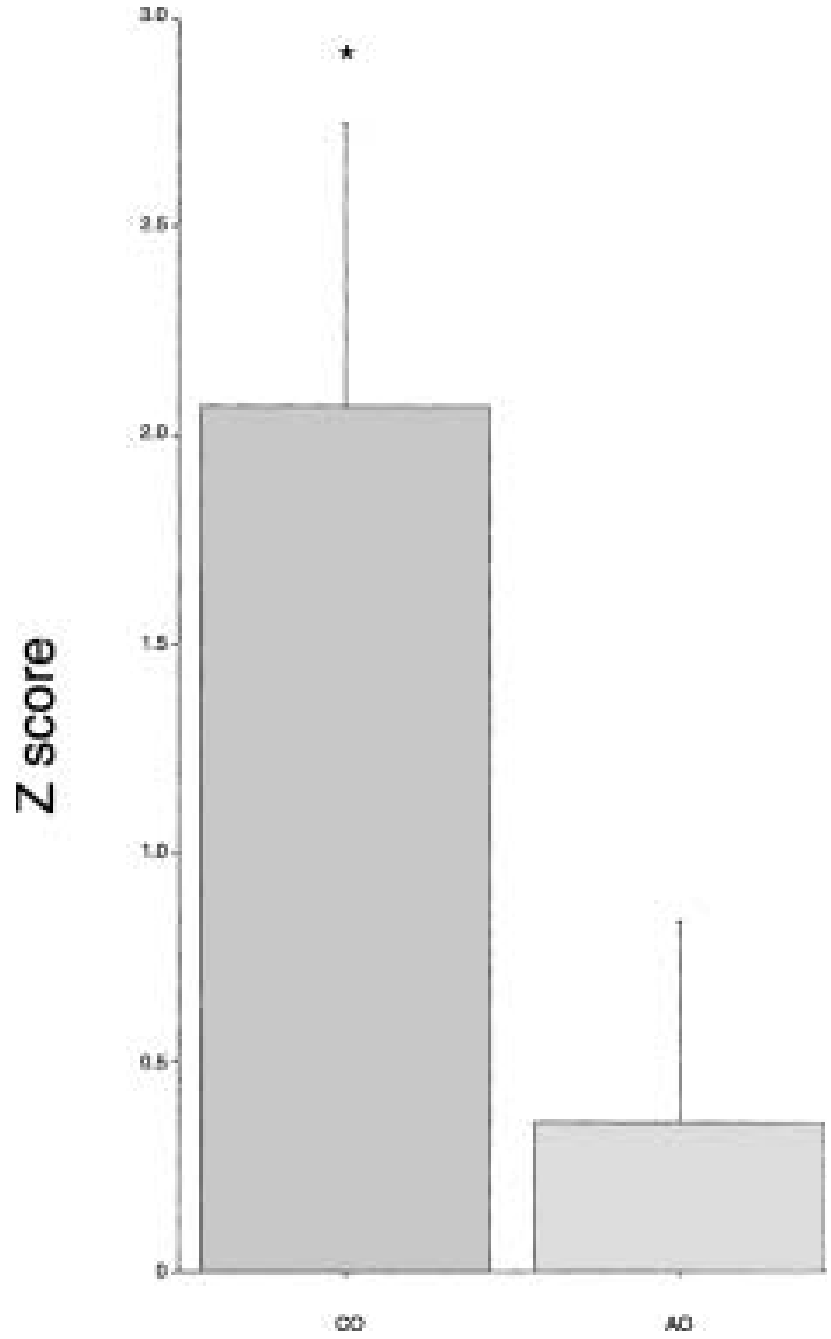

Figure 2 Comparison of the $Z$ score of IMT in CO-AGHD and AO-AGHD. The values represent the means \pm s.E.M. ${ }^{\star} P<0.05$ vs AO-AGHD.

and CO controls. IMT/BMI was still significantly higher in CO patients than CO controls $(0.036 \pm 0.016$ vs $0.029 \pm 0.007, P<0.05)$. There was no significant difference in absolute values of IMT among $\mathrm{CO}$ and AO patients. However, the IMT increases as a variable dependent on age in normal subjects, so the $\mathrm{Z}$ score of the IMT was calculated in each patient. The Z score of IMT was significantly higher in $\mathrm{CO}$ patients than in AO patients $(2.07 \pm 0.68$ vs $0.35 \pm 0.48$, $P<0.05$ ) (Fig. 2).

\section{Discussion}

It is well known that GH deficiency causes increased body fat with a decrease in lean body mass and abnormal levels of serum lipids and lipoproteins irrespective of racial difference (24). In addition, increased insulin resistance in peripheral tissues, decreased fibrinolytic activities, abnormal cardiac structure and performance, and premature atherosclerosis with increased arterial IMT have been reported in Caucasian patients with GH deficiency $(1-3,7,13,16)$, all of which might be responsible for an increased incidence of cardiovascular morbidity and mortality (1).

Asian people, including Japanese, have their own customs and conventions, different from Caucasians', particularly preference for food, and furthermore, the body constitution of Asian people is also different from that of Caucasian people, probably due to differences in genetic and environmental backgrounds. Therefore, it is of considerable interest whether Asian patients with GH deficiency are exposed to the risk of premature atherosclerosis in the same way as Caucasian patients. There are no convincing reports regarding the morbidity and mortality in Asian patients with GH deficiency.

To assess the development of premature atherosclerosis, we decided to measure the IMT of common carotid arteries, since an increased IMT is known to be the most sensitive parameter of atherosclerotic changes and to be detected without obvious abnormalities of the classic vascular risk factors $(23,25-27)$. In this study, we found that the IMT of the common carotid arteries was significantly increased in AGHD irrespective of timing of the disease onset. Our findings were not completely consistent with the findings of the pioneer study in Caucasian patients by Markussis et al. (2). The IMT in our AO-AGHD patients was $0.79 \mathrm{~mm}$ on the average, which was comparable to $0.72 \mathrm{~mm}$, the value in their patients aged 40-60 years. In contrast, the IMT, $0.82 \mathrm{~mm}$ on the average, in our CO-AGHD patients aged $29 \pm 7$ years seems to be unexpectedly great since the IMT was $0.50 \mathrm{~mm}$ among the patients less than 40 years of age in Markussis' study. Besides, our IMT data of CO-AGHD patients were consistent with a more recent report by Capaldo et al. (3) that the IMT was as great as $0.83 \mathrm{~mm}$ in the COAGHD aged $25 \pm 1$ years, comparable to that in our patients. These discrepancies may simply be caused by the difference among methods for IMT measurement. Our method is, of course, a valid (23) and previously reported method.

On the other hand, there is no report comparing the IMT of AGHD patients of $\mathrm{CO}$ and $\mathrm{AO}$ in one study. As mentioned above, our CO- and AO-AGHD patients showed greater IMT of the carotid arteries than the respective control subjects. There was no significant difference in the absolute values of IMT between $\mathrm{CO}$ and $\mathrm{AO}$ patients. This finding appeared to be unusual since the carotid artery IMT would be age-dependently increased in normal subjects. Then we further calculated the Z score of the IMT in each AGHD patients using the normal Japanese IMT values of every 10 year age cohort (23). It is of interest that the $\mathrm{Z}$ score of IMT was significantly higher in $\mathrm{CO}$ patients than 
AO patients, suggesting that $\mathrm{CO}$ patients have a greater risk of early development of atherosclerosis.

The reason why premature atherosclerosis is more prevalent in $\mathrm{CO}$ patients continues to be unclear. The simple explanation would be that these findings are due to the longer duration of $\mathrm{GH}$ deficiency. Indeed, the duration of $\mathrm{GH}$ deficiency in our $\mathrm{CO}$ patients was significantly longer than that in AO patients.

Borson-Chazot et al. (4) reported that a 1-year $\mathrm{GH}$ treatment resulted in significant reduction in increased IMT of carotid arteries in GHD patients, giving strong evidence that $\mathrm{GH}$ itself affects carotid IMT. Their findings also indicate that carotid IMT is not completely fixed but rather reversible and changeable under certain circumstances. Carotid IMT is affected by many factors including serum lipids. In our study, serum lipid levels in $\mathrm{CO}$ patients tended to be higher than those in $\mathrm{AO}$ patients, although the difference was statistically not significant (Table 1). Furthermore, it is well known that nitric oxide (NO) is a mediator of vasodilatation, inhibition of platelet aggregation, leukocyte adhesion and inhibition of vascular smooth muscle cell growth. IGF-I induces NO in vascular endothelial cells and NO may mediate haemodynamic effects of recombinant GH in GHD patients $(28,29)$. In this study, IGF-I was really low in AGHD although we did not measure IGF-I levels in normal subjects who were of normal height. We thought that GHD patients indeed would have lower plasma IGF-I levels as well as NO production than normal subjects. Although IGF-I levels did not differ between $\mathrm{CO}$ and $\mathrm{AO}$ patients (Table 1), CO patients were significantly younger than AO patients. Since it is well known that IGF-I levels progressively decline with increasing age, it would be biologically plausible that IGF-I levels in $\mathrm{CO}$ patients were markedly lower than in $\mathrm{AO}$ patients. Indeed, this difference could explain why CO patients had a higher $\mathrm{Z}$ score of IMT than AO patients. Hence, an enhanced effect through the combination of GHD as well as lower IGF-I levels for age and lipid abnormalities may simply be attributed to the greater Z score of IMT in CO patients.

In summary, this study demonstrated for the first time that carotid IMT in Japanese AGHD patients is increased as much as in Caucasian patients. Furthermore, Japanese CO-AGHD patients showed greater IMT than AO-AGHD patients, although the reason remains to be clarified.

\section{Acknowledgements}

We are grateful to Miss Chika Ogata for excellent technical assistance. This work was supported in part by Grants-in-Aid from the Japanese Ministry of Health and Welfare, and Growth Science Foundation in Japan.

\section{References}

1 Rosen T \& Bengtsson BA. Premature mortality due to cardiovascular disease in hypopituitarism. Lancet 1990336 285-288.

2 Markussis V, Beshyah SA, Fisher C, Sharp P, Nicolaides AN \& Johnston DG. Detection of premature atherosclerosis by highresolution ultrasonography in symptom-free hypopituitary adults. Lancet $1992 \mathbf{3 4 0} 1188-1192$.

3 Capaldo B, Patti L, Oliviero U, Longobardi S, Pardo F, Vitale F et al. Increased arterial intima-media thickness in childhood-onset growth hormone deficiency. Journal of Clinical Endocrinology and Metabolism 199782 1378-1381.

4 Borson-Chazot F, Serusclat A, Kalfallah Y, Ducottet X, Sassolas G, Bernard $S$ et al. Decrease in carotid intima-media thickness after one year growth hormone (GH) treatment in adults with $\mathrm{GH}$ deficiency. Journal of Clinical Endocrinology and Metabolism 1999 84 1329-1333.

5 Merimee TJ, Hollander W \& Fineberg SE. Studies of hyperlipidemia in the HGH-deficient state. Metabolism: Clinical and Experimental 197221 1053-1061.

6 Libber SM, Plotnik LP, Johanson AJ, Blizzard RM, Kwiterovich PO \& Migeon CJ. Long-term follow-up of hypopituitary patients treated with human growth hormone. Medicine 199069 46-55.

7 Rosen T, Eden S, Larson G, Wilhelmsen L \& Bengtsson B- $\AA$. Cardiovascular risk factors in adult patients with growth hormone deficiency. Acta Endocrinologica 1993129 195-200.

8 DeBoer H, Blok GJ, Voerman HJ, Philips M \& Schouten JA. Serum lipid levels in growth hormone-deficient men. Metabolism: Clinical and Experimental 199443 199-202.

9 Cuneo RC, Salomon F, Watts GF, Hesp R \& Sönksen PH. Growth hormone treatment improves serum lipids and lipoproteins in adults with growth hormone deficiency. Metabolism: Clinical and Experimental 199342 1519-1523.

10 Snel YEM, Doerga ME, Brummer RJM, Zelissen PMJ \& Koppeschaar HPF. Magnetic resonance imaging-assessed adipose tissue and serum lipid and insulin concentrations in growth hormone-deficient adults. Arteriosclerosis, Thrombosis, and Vascular Biology 199515 1543-1548.

11 Alford F, Hew FL, Koschmann M, Cristopher M, Rantzau C \& Ward G. Defects of glucose metabolism in growth hormonedeficient (GHD) adults. Endocrinology and Metabolism 19941 (Suppl B) 27.

12 O'Neal DN, Kalfas A, Dunning PL, Christopher MJ, Sawyer SD, Ward GM et al. The effect of 3 months of recombinant human growth hormone $(\mathrm{GH})$ therapy on insulin and glucose-mediated glucose disposal and insulin secretion in GH-deficient adults: a minimal model analysis. Journal of Clinical Endocrinology and Metabolism 199479 975-983.

13 Hew FL, Koschmann M, Christopher M, Rantzau C, Vaag A, Ward G et al. Insulin resistance in growth hormone-deficient adults: defects in glucose utilization and glycogen synthase activity. Journal of Clinical Endocrinology and Metabolism 199681 555-564.

14 Whitehead HM, Boreham C, McIlrath EM, Sheridan B, Kennedy L, Atkinson $\mathrm{AB}$ et al. Growth hormone treatment of adults with growth hormone deficiency: results of a 13-month placebo controlled cross-over study. Clinical Endocrinology 199236 45-52.

15 Beshyah SA, Freemantle C, Shahi M, Anyaoku V, Merson S, Lynch $S$ et al. Replacement treatment with biosynthetic growth hormone in growth hormone-deficient hypopituitary adults. Clinical Endocrinology $1995 \mathbf{4 2} 73-84$.

16 Amato G, Carella C, Fazio S, La Montagna G, Cittadini A, Sabatini $\mathrm{D}$ et al. Body composition, bone metabolism, and heart structure and function in growth hormone (GH)-deficient adults before and after GH replacement therapy at low doses. Journal of Clinical Endocrinology and Metabolism 199377 1671-1676.

17 Nass R, Huber RM, Klauss V, Muller OA, Schopohl J \& Strasburger CJ. Effect of growth hormone (hGH) replacement therapy on physical work capacity and cardiac and pulmonary function in patients with hGH deficiency acquired in adulthood. Journal of Clinical Endocrinology and Metabolism $1995 \mathbf{8 0} 552-557$. 
18 Rutherford OM, Beshyah SA, Scon J, Watkins Y \& Johnston DG. Contractile properties of the quadriceps muscle in growth hormone-deficient hypopituitary adults. Clinical Science $1995 \mathbf{8 8}$ $67-71$.

19 Valcavi R, Gaddi O, Zini M, Iavicoli M, Mellino U \& Portioli I. Cardiac performance and mass in adults with hypopituitarism: effects of one year of growth hormone treatment. Journal of Clinical Endocrinology and Metabolism $1995 \mathbf{8 0}$ 659-666.

20 McGauley GA. Quality of life assessment before and after growth hormone treatment in adults with growth hormone deficiency. Acta Pediatrica Scandinavica 1989356 70-72.

21 Mardh G, Lundin K, Borg G, Jonsson B \& Lindeberg A. Growth hormone replacement therapy in adult hypopituitary patients with growth hormone deficiency: combined data from 12 European placebo-controlled clinical trials. Endocrinology and Metabolism 19941 (Suppl A) 43-49.

22 Attanasio AF, Lamberts WJS, Matranga MCA, Birkett MA, Bates PC \& Valk NK. Adult growth hormone (GH)-deficient patients demonstrate heterogeneity between childhood onset and adult onset before and during human GH treatment. Journal of Clinical Endocrinology and Metabolism 199782 82-88.

23 Yamasaki Y, Kawamori R, Matsushima H, Nishizawa H, Kodama M, Kajimoto Y et al. Atherosclerosis in carotid artery of young IDDM patients monitored by ultrasound high-resolution B-mode imaging. Diabetes $199443634-639$.

24 Irie M, Shizume K, Takano K, Kato Y, Tanaka T \& Chihara K. Growth hormone replacement therapy in adults with growth hormone deficiency: a double blind, placebo-controlled crossover trial in Japan. Endocrinology and Metabolism 19952 17-23.

25 Powrie J, Weissberger A \& Sönksen P. Growth hormone replacement therapy for growth hormone-deficient adults. Drugs 1995 $49656-663$.

26 Pignoli P, Tremoli E, Poli A, Oreste P \& Paoletti R. Intimal plus medial thickness of the arterial wall: a direct measurement with ultrasound imaging. Circulation 198674 1399-1406.

27 Bonithon-Kopp C, Touboul P-J, Berr C, Leroux C, Mainard F, Courbon $\mathrm{D}$ et al. Relation of intima-media thickness to atherosclerotic plaques in carotid arteries. The vascular aging (EVA) study. Arteriosclerosis, Thrombosis, and Vascular Biology $199616310-316$.

28 Tsukahara H, Gordienko DV, Tonshoff B, Gelalto MC \& Goligorsky MS. Direct demonstration of insulin-like growth factor-I-induced nitric oxide production by endothelial cells. Kidney International 199445 598-604.

29 Böger RH, Skamira C, Bode-Böger SM, Brabant G \& Mühlen A. Nitric oxide may mediate hemodynamic effects of recombinant growth hormone in patients with acquired growth hormone deficiency. A double-blind, placebo-controlled study. Journal of Clinical Investigation $1996 \mathbf{9 8} 2706-2713$.

Received 3 April 2002

Accepted 11 December 2002 